\title{
Worst Prognosis in the "Complex" Jejunoileal Atresia: Is It Real?
}

\author{
Silvana Federici ${ }^{1} \quad$ Maria Domenica Sabatino $^{1} \quad$ Vincenzo Domenichelli $^{1} \quad$ Simona Straziuso $^{1}$ \\ ${ }^{1}$ Department of Pediatric Surgery, Infermi Hospital, Rimini, Italy \\ Address for correspondence Maria Domenica Sabatino, Department \\ Eur J Pediatr Surg Rep 2015;3:7-11. \\ of Pediatric Surgery, Infermi Hospital, via Settembrini 2, Rimini 47921, \\ Italy (e-mail: maria_sabatino@libero.it).
}

\begin{abstract}
Keywords

- complex case

- jejunoileal atresia

- prognosis

Objective This report documents the authors' experiences in the management of "complex" jejunoileal atresia (JIA) and provides a review of the recent literature on "simple" and "complex" JIA.

Materials and Methods This is a retrospective study of eight cases of "complex" JIA managed at the Pediatric Surgical Unit of Infermi Hospital in Rimini from 2002 to 2012. The inclusion criteria are all cases of JIA associated with distal bowel deformities and Types IIIb or IV. One patient had gastroschisis.

Results The authors of this study performed primary anastomosis on three patients and enterostomies on five patients. In one case in which a patient presented with gastroschisis, the V.A.C. Therapy System (KCl Medical Ltd., Langford Locks, Kidlington, UK) was used to close the abdominal defect. All patients needed central venous catheter (CVC). Total parenteral nutrition (TPN) was administered for a mean of 12 days. Oral feeding was introduced on mean day 7 ( $7.71 \pm 3.40$ standard deviation). Patients with enterostomy began extracorporeal stool transport on mean day 14 . No outcomes resulted in short bowel syndrome (SBS). The mortality rate was zero. The authors of this study performed more enterostomies and CVC insertion than other authors in "complex" JIA and reported a percentage of SBS, complications of TPN, and start of oral feeding comparable to "simple" case reported by other authors.

Conclusions The results demonstrate that the complexity of JIA alone is not associated to a worsening prognosis than simple atresia if the surgical and clinical approach is as conservative as possible.
\end{abstract}

\section{Introduction}

The jejunoileal atresia (JIA) is a rare congenital malformation, which occurs in 1 of 5,000 newborns. ${ }^{1}$ It may occur in either the jejunum or the ileum, with single atresias being significantly more common (90\%) than multiple ones (10\%). Grosfeld et al classified these malformations in Types I-IIIIIa-IIIb-IV. ${ }^{2}$ The Type IIIb, the so-called apple peel small bowel syndrome, is one of the most severe intestinal malformations even if it is the most uncommon form of congenital intestinal atresia which was first described by Santulli and
Blanc $^{3}$ as an occlusion of the proximal jejunum associated to an absence of gross parts of the mesentery and variable large parts of the small intestine with a characteristic helical appearance of the preserved terminal ileum. Many studies confirmed $^{4-7}$ that the mortality in case of intestinal atresia have decreased steadily throughout the 20th century from $90^{6}$ to $16 \% .^{5,8,9}$ Thanks to the improvements in neonatal anesthetic and surgical techniques and the use of total parenteral nutrition (TPN). ${ }^{5}$ There is a recent literature focusing on complex cases of jejunal atresia (JA) that are associated with a much higher morbidity and mortality than received

September 10, 2013

accepted after revision

December 29, 2013

published online

July 17, 2014

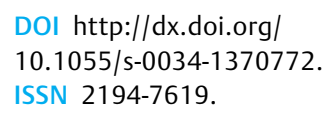

DOI http://dx.doi.org/

10.1055/s-0034-1370772. ISSN 2194-7619.

(c) 2015 Georg Thieme Verlag KG
Stuttgart . New York

License terms

(요 (1) $\Theta \circledast$ 


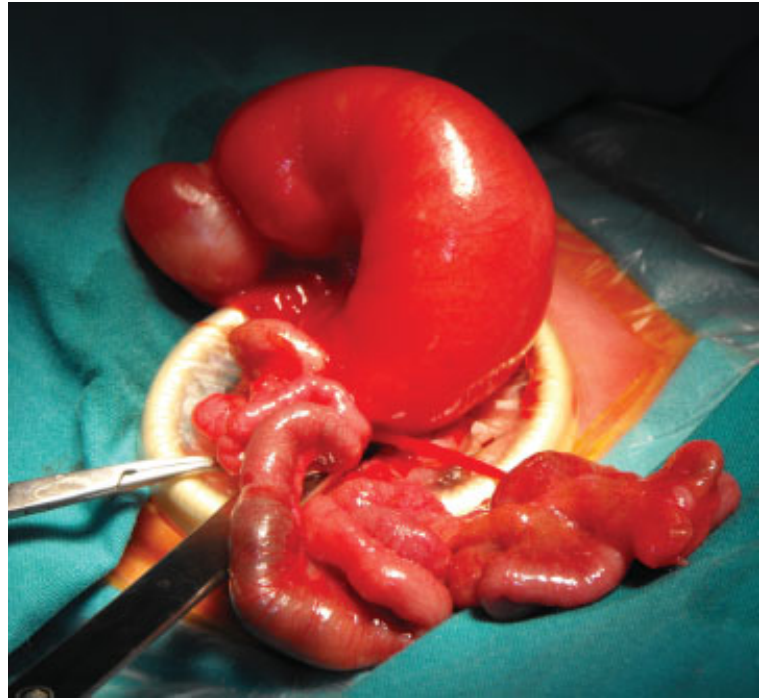

Fig. 1 Case of high jejunal atresia and distal apple peel deformity

that associated with simple cases ${ }^{10}$ and that may also be associated with complicated postoperative management after surgical correction. We are reporting our experience in the management of complex cases of JIA and reviewing the results described in literature.

\section{Materials and Methods}

This is a retrospective study of eight cases of complex JIA managed at our Unit of Pediatric Surgery from January 2002 to July 2012. We used the same criteria of inclusion reported by Lee et al for "complex" JA $\mathrm{A}^{10}$ : all cases of JIA associated to distal bowel deformities and Type IIIb ( - Fig. 1) or IV ( - Fig.2), according to the classification of Grosfeld et $\mathrm{al}^{2}$ ( - Table 1 ).

of the eight patients, four were female and four were male with a ratio of $1: 1$. All patients were premature babies with a

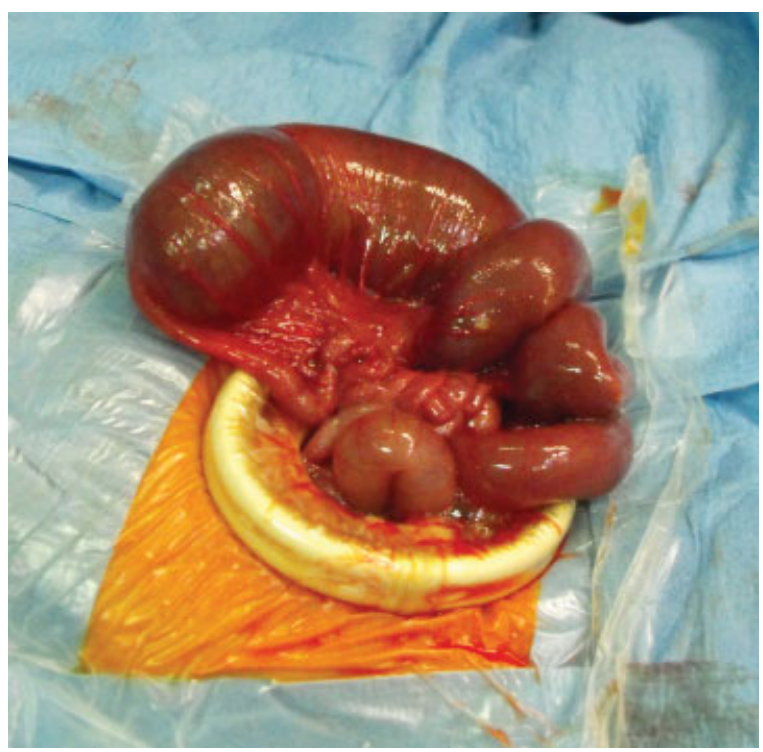

Fig. 2 Case of high jejunal atresia with multiple atresia. median gestational age of 35 weeks (range, $34^{5 / 7}-35^{6 / 7}$ weeks). Two patients (25\%) were bichorionic and monozygotic twins. A correct prenatal diagnosis was made in seven of eight patients (87.5\%). In four patients, the prenatal diagnosis of upper small bowel obstruction was made between the 20th and 33rd week of gestation and in one case it was made the day before delivery.

Polyhydramnios was present in one patient. In another one, the prenatal diagnosis was of gastroschisis. The mean birth weight was 2,580 g (range, 1,895-3,265 g). Approximately $71.5 \%$ of the patients were born through a cesarean delivery and $28.5 \%$ through vaginal delivery. One patient had a gastroschisis as an associated congenital malformation.

The surgical approach was based on morphologic findings. The medical records of the patients were reviewed and the data were collected regarding definite features: number of primary anastomosis (PA) and enterostomies, number of patient who need TPN and its duration in the postoperative period, start of oral feeding, postoperative complications, number of patients who developed SBS, and time of hospital stay. We used the term of SBS if less than 50,75 , or $100 \mathrm{~cm}$ of residual small bowel was present for premature newborns (between 28 and 35 weeks of gestational age), term newborns or older children, respectively. The follow-up ranged from the age of 6 months to 2 years.

We are reporting our results and reviewing the studies published in the literature about "complex" and "simple" cases of JIA according Grosfeld classification.

\section{Results}

There were no signs of intestinal malformation in twins. We performed three of eight (37.5\%) PA and five of eight (62.5\%) jejunoileostomy (three jejunostomy-two ileostomy). Of eight, four (50\%) limited intestinal resection associated to tapering. In three patients with multiple atresias, we found six atresias in one case, seven atresias in another case, and eight atresias in the other one. We performed 3, 5, and 6 PA, respectively. If we compare the percentage of enterostomies and PA reported in the literature with those performed in our study at chi-square test, we have a statistical significant difference $(p<0.01)$ ( - Table 2 ).

The case associated to gastroschisis was treated with an abdominal wall "Silo" to reduce the herniated intestinal content and on the 13th day of life an intestinal resection and primary ileocolic anastomosis was performed. The primary closure of the abdominal defect was not possible because of wall tension. Vacuum assisted closure (V.A.C. Therapy System; KCI Medical Ltd., Langford Locks, Kidlington, UK) Therapy System was used to close the abdominal wall. The V.A.C. Therapy System was used in continuous mode at $25 \mathrm{~mm} \mathrm{Hg}$. The dressing was changed every 48 to 72 hours.

In all the patients, a central venous catheter (CVC) was inserted. In two patients, we inserted a Broviac (Vygon $\mathrm{GmbH}$ \& Co. KG, Aachen, Germany) catheter and in six patients we positioned a percutaneous catheter for TPN or partial parenteral nutrition (PPN) after initial postoperative oral feeding. The TPN was administered for a mean period of $12 \pm 3$ days 
Table 1 Data of patients

\begin{tabular}{|c|c|c|c|c|c|}
\hline Patient & Age at birth & $\begin{array}{l}\text { Weight at } \\
\text { birth }(g)\end{array}$ & $\begin{array}{l}\text { Prenatal } \\
\text { diagnosis }\end{array}$ & Type of malformation & Associated malformation \\
\hline F.Z.N. & 34 wks $+5 d$ & 2,850 & Yes & $\begin{array}{l}\text { High JA associated to a "ball" } \\
\text { morphology of bowel loops, } \\
\text { without the true "apple peel" } \\
\text { structure with a normal intestinal } \\
\text { length. Absence of ileocecal valve } \\
\text { and cecoappendicular agenesis }\end{array}$ & No \\
\hline S.P. & 34 wks $+5 d$ & 3,265 & Yes & $\begin{array}{l}\text { High JA and distal apple peel } \\
\text { deformity (- Fig. 1) }\end{array}$ & No \\
\hline P.S. & $35 w k s+2 d$ & 2,810 & Yes & High JA with multiple atresia (-Fig. 2) & No \\
\hline S.M. & 35 wks & 1,895 & No & $\begin{array}{l}\text { High JA with multiple atresia and } \\
\text { transverse colon atresia }\end{array}$ & No \\
\hline S.L. & 33 wks & 2,200 & Yes & $\begin{array}{l}\text { Multiple jejunal atresia and apple } \\
\text { peel syndrome }\end{array}$ & No \\
\hline P.S. & $34 w k s+5 d$ & 2,575 & Yes & High JA with multiple atresia & No \\
\hline A.D. & $34 w k s+5 d$ & 2,900 & Yes & High JA with distal volvulus & No \\
\hline M.I. & $35 w k s+3 d$ & 2,090 & Yes & JIA with apple peel syndrome & Gastroschisis \\
\hline
\end{tabular}

Abbreviations: JA, jejunal atresia; JIA, jejunoileal atresia

(median, 11 days). The parenteral nutrition support (TPN and PPN) was administered for mean $39.75 \pm 19.71$ days. These data are comparable to the one reported by other authors in case of "simple" JA (32.3 \pm 17.5 days) $(p>0.05 \%$ at Student t-test). ${ }^{11}$

Postoperative oral feeding was started on mean day 7.71 \pm 3.40 (range, 3-13 days) (median, 7 days) except for the case associated to gastroschisis who had intestinal obstruction. Fully caloric enteral intake was reached after a median of 40 postoperative days (range, 15-60 days). One case had sepsis for infection of the CVC site resolved by antibiotic treatment. The start of oral feeding in our study has no statistical significant difference at Student $t$-test ( $p>0.05 \%)$, if it is compared with that reported by other authors $^{5,11}$ in "simple" cases of JIA $5.4 \pm 4.3$.

The patient with intestinal obstruction underwent a second surgical procedure on the 23rd postoperative day. At laparotomic exploration, we observed dilated jejunoileal loops with dehiscence of the previous anastomosis and a

Table 2 Enterostomies and primary anastomosis rate of current and different studies published in the literature

\begin{tabular}{|c|c|c|}
\hline References & Enterostomies (\%) & $\begin{array}{l}\text { Primary } \\
\text { anastomosis } \\
(\%)\end{array}$ \\
\hline Current study & 62 & 37.5 \\
\hline Sato et al ${ }^{11}$ & 0 & 100 \\
\hline Kumaran et $\mathrm{al}^{9}$ & 10 & 90 \\
\hline $\begin{array}{l}\text { Festen et al } \\
\text { (Type IIIb) }\end{array}$ & 20 & 67 \\
\hline Stollman et $\mathrm{al}^{5}$ & 26 & 69 \\
\hline Lee et $\mathrm{al}^{10}$ & 14.3 & 90.9 \\
\hline
\end{tabular}

colic dilation beneath for a tract of $2 \mathrm{~cm}$. An intestinal resection-including the previous anastomosis and the tract of dilated colon-was made and an ileostomy and colostomy were performed. The abdominal wound was definitively closed. The patients with jejunoileostomy began extracorporeal stool transport (EST) on mean 14th postoperative day. Reintroduction of enteral fluids from the proximal stoma to the distal one reduced the need for parenteral fluid and electrolytes and helped the development of enteral villi.

The patients with enterostomies (65\%) required a surgical approach to close the jejunoileostomy to restore intestinal continuity by an end-to-end anastomosis 1 to 2 months from the first operation. The second postoperative period was also uneventful for all patients and total enteral feeding was achieved in mean of 10 days.

Our data showed $0 \%$ of SBS with a statistical significant difference ( $p<0.05 \%$ at Student $t$-test) than data published in literature (17-30\%) about "complex" case of JIA (-Table 3). The mortality rate was $0 \%$. The mean hospital stay was $54.37 \pm 31$ days.

\section{Discussion}

JIA is a common cause of neonatal intestinal obstruction. The management of neonates with JIA has improved because of refinements in neonatal intensive care, operative techniques, use of TPN and anesthesia. ${ }^{5,8,12}$ Many authors ${ }^{5,8}$ showed a decreased mortality rate in the past 15 years, associated to increasing cost for the managing of the surviving children with a significant increase of late complications. ${ }^{5}$ Multiple factors affect intestinal atresia outcomes including low birth weight, prematurity, length of the remaining bowel, preservation of ileocecal valve, ${ }^{13}$ and associated anomalies. ${ }^{5,11}$ 
Table 3 Short bowel syndrome rate of current and different studies published in the literature

\begin{tabular}{|l|l|}
\hline References & Short bowel syndrome (\%) \\
\hline Current study & 0 \\
\hline Dalla Vecchia et al $^{8}$ & 14 \\
\hline Festen et al $^{16}$ & 13 JIA Type IIIb \\
\hline Stollman et al & 8 JIA Types I-II-IIla \\
& 32 JIA Types IIIb-IV \\
\hline Lee et al $^{10}$ & 33 "complex" JA \\
\hline
\end{tabular}

Abbreviations: JA, jejunal atresia; JIA, jejunoileal atresia.

In our series, all patients were premature and this factor was not associated to worst prognosis. Some authors ${ }^{10}$ suggested that the association between prematurity and all cases of high JA and multiple atresia and agenesis of distal segment could imply that malformative process may be involved in the development of complex cases, contrary to classic theory of vascular mesenteric accidents supported by high association between JA and other gastrointestinal anomaly, especially malrotation. ${ }^{14}$

Other authors supposed a malformative process as cause of JA observing a subgroup of JA who had extraintestinal malformations in association with atresia. It would appear that these patients were subject to an early in utero insult that interfered with embriogenesis. ${ }^{5}$

In our series, the absence of gastrointestinal anomalies in twin and the absence of extraintestinal malformation in $87.5 \%$ of patients, could not support the malformative theory but suggest that vascular accident could be the reason behind the malformation even if the prematurity could suggest an early in utero insult.

SBS is still the largest problem in neonates with JIA that occurs in approximately $15 \%$ of JIA after resection. ${ }^{5}$ This condition required long-term management with prolonged TPN and additional surgical procedures.

Nevertheless, prolonged TPN necessarily experienced a chronic cholestasis. Lee et al reported the largest series of complex JIA. The authors showed how a complex JA is associated to higher morbidity than less complex cases. ${ }^{10}$ The authors underlined that the complex JA required a most aggressive surgical approach with resection that resulted in higher percentage of SBS, $36 \%$ of cases compared with $17 \%^{5}$ of other series of less complex JAs. The need for TPN and additional operative procedure as STEP (serial transverse enteroplasty) in the management of SBS resulted in longer hospitalization and experienced a delay in enteral feeding.

Our series had the peculiarity that none of the patients had an associated congenital malformation except the one associated to gastroschisis, so the outcome of the patients was not conditioned by them. Operative management of the cases was based on morphologic findings. According to some authors, ${ }^{13}$ we found an advantage in resecting the proximally dilated bowel segment when an adequate length of the remaining bowel could be preserved, which made the anastomosis between bowels with a large disparity in diameter less difficult. In cases of inadequate bowel length, we performed limited resection and tapering of the dilated jejunum. This approach had a recovery of bowel function within a reasonable period as well as those who underwent bowel resection. In cases where the bowel viability is questionable or a diameter difference between the proximal and distal part is $1: 5{ }^{8}$ we performed enterostomies. We performed $37.5 \%$ of PA and $62 \%$ of enterostomies. From a review of the literature about JIA published in the last 10 years, the authors reported a percentage of PA of 67 to $100 \%$ and of temporary enterostomies of 0 to $26 \%^{5,9,11,15,16}$ Lee et al ${ }^{10}$ reported $14.3 \%$ of ileostomy and $90.9 \%$ of PA in "complex" JA ( - Table 2).

We performed more enterostomies and less PA than the other authors ${ }^{5,9-11,15,16}$. Our surgical choice permitted to preserve as much length of bowel as possible reducing the risk of SBS and the duration of TPN even in "complex" cases. According to some authors, ${ }^{14}$ patients with gastroschisis needed a significantly longer duration of parenteral nutritive support (64 days) than the other patients without congenital malformation. Nevertheless, the EST procedure used in case of enterostomies confirmed that the EST established a physiological nutrition in neonate with stomas, allowing an early oral feeding comparable as "simple" case of JIA published in literature ${ }^{11}$ and decreasing the risk of cholestasis ${ }^{17}$ due to prolonged TPN. The EST permitted to prepare the bowel to recanalization reducing the disparity of caliber between the bowel loops as shown by the study of Schäfer et al. ${ }^{18}$

The use of V.A.C. System Therapy in the closure of abdominal defect of gastroschisis was associated with cleansing of the wound and maintenance of a sterile environment. It permitted to perform a rapid definitive closure of wound (23 days). Few studies $^{19,20}$ are published in literature about the use of V.A.C. System Therapy in abdominal wound of neonates. The authors showed that V.A.C. System Therapy device should be considered a safe and effective alternative in treating giant omphalocele or complicate neonatal abdominal wounds. ${ }^{17,18}$

\section{Conclusion}

Our results showed that the complexity of JIA alone, without other congenital malformations, is not associated to a worse prognosis than simple atresias considering the beginning of oral enteral feeding, postoperative complications, length of TPN, and percentage of SBS. Nevertheless, the complex case requires a surgical approach not as aggressive as the complexity of malformation could suggest but based on more steps to allow an earlier oral feeding and shorter TPN period.

\section{Conflict of Interest}

None.

\section{References}

1 Buyse ML, ed. Birth Defects Encyclopedia. Cambridge, MA: Blackwell Scientific Publications; 1990:993-994

2 Grosfeld JL, Ballantine TV, Shoemaker R. Operative management of intestinal atresia and stenosis based on pathologic findings. J Pediatr Surg 1979;14(3):368-375 
3 Santulli TV, Blanc WA. Congenital atresia of the intestine: pathogenesis and treatment. Ann Surg 1961;154:939-948

4 Rescorla FJ, Grosfeld JL. Intestinal atresia and stenosis: analysis of survival in 120 cases. Surgery 1985;98(4):668-676

5 Stollman TH, de Blaauw I, Wijnen MHWA, et al. Decreased mortality but increased morbidity in neonates with jejunoileal atresia; a study of 114 cases over a 34-year period. J Pediatr Surg 2009;44(1):217-221

6 Evans $\mathrm{CH}$. Atresias of the gastrointestinal tract. Int Abstr Surg 1951;92(1):1-8

7 Louw JH, Barnard CN. Congenital intestinal atresia; observations on its origin. Lancet 1955;269(6899):1065-1067

8 Dalla Vecchia LK, Grosfeld JL, West KW, Rescorla FJ, Scherer LR, Engum SA. Intestinal atresia and stenosis: a 25-year experience with 277 cases. Arch Surg 1998;133(5):490-496, discussion 496-497

9 Kumaran N, Shankar KR, Lloyd DA, Losty PD. Trends in the management and outcome of jejuno-ileal atresia. Eur J Pediatr Surg 2002;12(3):163-167

10 Lee SH, Cho YH, Kim HY, Park JH, Byun SY. Clinical experience of complex jejunal atresia. Pediatr Surg Int 2012;28(11):1079-1083

11 Sato S, Nishijima E, Muraji T, Tsugawa C, Kimura K. Jejunoileal atresia: a 27-year experience. J Pediatr Surg 1998;33(11):1633-1635

12 Michaud L, Guimber D, Labouré S, Bonnevalle M, Gottrand F, Turck D. Cystic fibrosis is a cause of apple peel syndrome. J Pediatr Gastroenterol Nutr 1999;29(1):107-108
13 Piper HG, Alesbury J, Waterford SD, Zurakowski D, Jaksic T. Intestinal atresias: factors affecting clinical outcomes. J Pediatr Surg 2008;43(7):1244-1248

14 Sweeney B, Surana R, Puri P. Jejunoileal atresia and associated malformations: correlation with the timing of in utero insult. J Pediatr Surg 2001;36(5):774-776

15 Burjonrappa SC, Crete E, Bouchard S. Prognostic factors in jejunoileal atresia. Pediatr Surg Int 2009;25(9):795-798

16 Festen S, Brevoord JCD, Goldhoorn GA, et al. Excellent long-term outcome for survivors of apple peel atresia. J Pediatr Surg 2002; 37(1):61-65

17 Federici S, Domenichelli V, Antonellini C, Dòmini R. Multiple intestinal atresia with apple peel syndrome: successful treatment by five end-to-end anastomoses, jejunostomy, and transanastomotic silicone stent. J Pediatr Surg 2003;38(8):1250-1252

18 Schäfer K, Schledt A, Linderkamp O, Gfrörer S, Roth H. Decrease of cholestasis under "continuous extracorporeal stool transport (CEST)" in prematures and neonates with stomas. Eur J Pediatr Surg 2000;10(4):224-227

19 Lopez G, Clifton-Koeppel R, Emil S. Vacuum-assisted closure for complicated neonatal abdominal wounds. J Pediatr Surg 2008; 43(12):2202-2207

20 Kilbride KE, Cooney DR, Custer MD. Vacuum-assisted closure: a new method for treating patients with giant omphalocele. J Pediatr Surg 2006;41(1):212-215 